Research Article

\title{
Cholecystokinin antagonists: Fluorinated 5-Hydroxy- 5-Aryl-Pyrrol-2-ones as experimental agents for brain, colon and pancreatic cancer
}

\section{Introduction}

In terms of cholecystokinin-physiology, ${ }^{1}$ CCK- 8 is the most common peptide hormone, which is extensively found throughout the gastrointestinal tract (GIT) and is also widely distributed through the nervous system. ${ }^{2}$ Originally, cholecystokinin was discovered to cause contractions of the gallbladder. ${ }^{3}$ It was then rediscovered as pancreozymin, triggering the release of pancreatic enzymes. Finally, it was confirmed that both peptides are identical. ${ }^{4}$ Cholecystokinin acts as a neuromodulator as well as gut hormone and the cholecystokinin receptor has been extensively investigated as potential drug targets. ${ }^{5}$ CCK-ligands, agonists and antagonists, ${ }^{6}$ have been extensively investigated as potential drug molecules. ${ }^{7}$ They were studied as growth inhibitors in certain forms of cancer, ${ }^{8}$ as anxiolytics, ${ }^{9}$ in the treatment of schizophrenia ${ }^{10}$ and satiety. ${ }^{11}$ Cholecystokinin does cause proliferation in colon- and pancreatic cancer cell lines and therefore, CCK-antagonists were studied as growth factor inhibitors in certain forms of cancer.

Asperlicin was the first non-peptidal lead structure from nature ${ }^{12}$ and analogues thereof were studied as CCK ligands. ${ }^{13}$ Simplification of this lead structure by Merck led to Devazepide, ${ }^{14}$ a potent $\mathrm{CCK}_{1}$ selective cholecystokinin antagonist (Figure 1), containing a 1,4-benzodiazepine template and an indole moiety. Proglumide ${ }^{15}$ was the first glutamic acid based agent, marketed as Milid for the treatment of ulcer. Lorglumide, a derivative of proglumide, ${ }^{16}$ (Figure 1) is one of several CCK receptor antagonists ${ }^{17}$ and served as experimental standard. The indolyl amide of devazepide was replaced by a urea linkage and Merck's L-365,260 resulted in a $\mathrm{CCK}_{2}$ selective antagonist. ${ }^{18} \mathrm{Z}-360$ is a $\mathrm{CCK}_{2}$-gastrin receptor antagonist and progressed into phase 2 trial with pancreatic cancer. ${ }^{19} \mathrm{Z}-360$ is the most recent derivative derived from this original lead structure, with improved selectivity and bioavailability.

All structural optimisations did only partly address the main underlying problem with respect to poor pharmacokinetic properties, such as a low water solubility and very low membrane penetration, as a result of a large polar surface area of the molecules and a relatively high molecular weight.

In our early search for new CCK ligands, in which the 1,4-benzodiazepine structure ${ }^{20}$ was replaced by an achiral diphenyl pyrazolone template, novel CCK antagonists with an indole carboxylic acid ${ }^{21}$ and a phenyl urea moiety ${ }^{22}$ were initially optimized as CNS drug with excellent animal data on anxiety and depression. ${ }^{23}$ The 1,4-benzodiazepine template was varied by a combinatorial solid phase synthesis ${ }^{24}$ and it was SAR optimized in terms of CCK binding affinity to a benzodiazepine with a simple propyl group. ${ }^{25}$

Again, having realized the poor pharmacokinetic properties these agents, a search for a completely novel, smaller template with a molecular weight $<350$, a $\log \mathrm{p}$ about 3 and a polar surface area for membrane penetration of less that $100 \mathrm{~A},{ }^{2}$ with no urea linkage was initiated.
Volume 9 Issue I - 2018

\author{
Eric Lattmann,' Ramesh Narayanan, ${ }^{2}$ Steven \\ t Russell,' Wayne A Fleary,' Mankaran Singh,' \\ PN Balaram, ${ }^{3}$ Pornthip Lattmann ${ }^{3}$ \\ 'School of Life and Health Sciences, Aston University, England \\ ${ }^{2}$ Department of Medicine, University of Tennessee Health \\ Science Center, USA \\ ${ }^{3}$ PNB Vesper Life Science PVT, India
}

Correspondence: Eric Lattmann, Aston School of Pharmacy, Aston University, Aston Triangle, Birmingham B4 7ET, England, Tel +44-(0) I2 I 204 3980, Fax 44-(0) I2 I 3590733 ,

Email e.lattmann@aston.ac.uk

Received: January 23, 2018 | Published: February 07, 2018

Aim of the drug discovery programme, initiated by PNB Vesper Life Sciences, was to systematically design from the $2(5 \mathrm{H})$-furanone scaffold $^{26}$ a hydroxyl-pyrrolone scaffold with ligands for both $\mathrm{CCK}_{1}$ and $\mathrm{CCK}_{2}$ pathways.

Initial results for CCK antagonists of the pyrrolone scaffold were communicated in the area of cancer therapeutics ${ }^{27}$ and inflammation. ${ }^{28}$ Here, a full biological evaluation of the cancer duo PNB-028 \& PNB291 will be reported in detail with respect to their antineoplastic properties. ${ }^{29}$

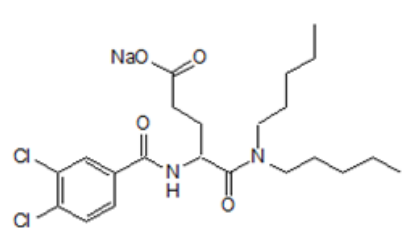

Lorglumide
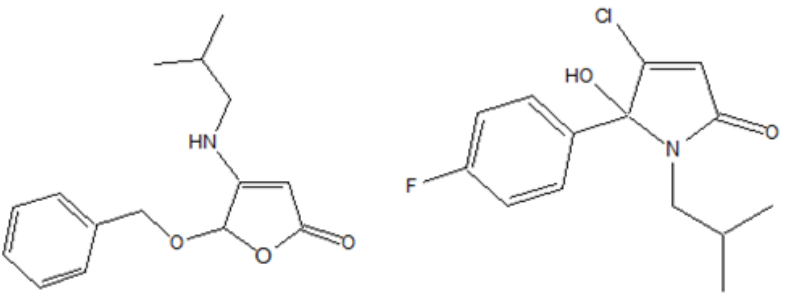

PNB -028

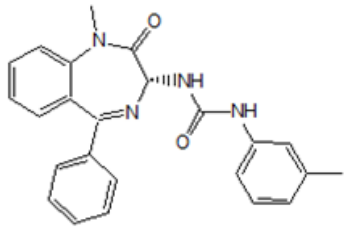

L-365,260
Figure I A pyrazolone based CCKI antagonist derived from 2(5H)-furanones. 


\section{Materials and methods}

\section{Experimental section}

.125I-CCK-8 Radioligand cholecystokinin binding assay: $\mathrm{CCK}_{2}$ and $\mathrm{CCK}_{1}$ receptor binding assays were performed, by using guinea pig cerebral cortex or rat pancreas. Male guinea pig brain tissues were prepared according to the modified method described by Saita et al. ${ }^{30}$ Pancreatic membranes were prepared as described by Charpentier et al. ${ }^{31}$. Tissues were homogenized in ice cold sucrose $(0.32 \mathrm{M}, 25 \mathrm{ml})$ for 15 strokes at $500 \mathrm{rpm}$ and centrifuged at $13000 \mathrm{rpm}$ for 10 minutes. The supernatant was re-centrifuged at $13000 \mathrm{rpm}$ for 20 minutes. The resulting pellet was re-dispersed to the required volume of buffer at $500 \mathrm{rpm}$ and stored in aliquots at $70^{\circ} \mathrm{C}$.

Binding was achieved using radioligand ${ }^{125}$ I-Bolton-Hunter labeled $\mathrm{CCK}, \mathrm{NEN}$ at $25 \mathrm{pM}$. The samples were incubated with membranes $(0.1 \mathrm{mg} / \mathrm{ml})$ in $20 \mathrm{mM}$ Hepes, $1 \mathrm{mM}$ EGTA, $5 \mathrm{mM} \mathrm{MgCl}, 150 \mathrm{mM}$ $\mathrm{NaCl}$, at $\mathrm{pH} 6.5$ for $2 \mathrm{hrs}$ at RT and then centrifuged at $11000 \mathrm{rpm}$ for 5 minutes. The membrane pellets were washed twice with water and the bound radioactivity was measured in a Packard Cobra Autogamma counter (B5005). Binding assays were carried out with L-363, 260 as control.

Isolated tissue preparations: Male Sprague Dawley rats, weighing 200-250g were used and all animal care and experimental protocols adhered to the relevant laws and guidelines of the institution. The animals were housed under standard conditions of temperature $\left(25^{\circ} \mathrm{C}\right)$ with unrestricted access to food and water. The animals were sacrificed using cervical dislocation without anaesthesia. From the abdomen of the animals, the duodenum was carefully excised and washed with physiological solution. The mesentery of the tissue was removed and the lumen was gently flushed with Tyrode's solution to clear luminal contents. The prepared isolated tissue was rapidly incubated in Tyrode's solution maintained at $32^{\circ} \mathrm{C}$ and gassed with $95 \% \mathrm{O}_{2} / 5 \% \mathrm{CO}_{2}$. Tyrode's solution was freshly prepared daily (g/l): $\mathrm{NaCl}, 8.0 ; \mathrm{KCl}, 0.2 ; \mathrm{CaCl}_{2}, 0.2 ; \mathrm{MgSO}_{4}, 0.1 ; \mathrm{NaH}_{2} \mathrm{PO}_{4}, 0.05$; $\mathrm{NaHCO}_{3}, 1.0$; Glucose, 1.0. The main equipment used was the Radnoti single unit tissue bath system with a chamber capacity of 35 $\mathrm{ml}$. Bath aeration with carbogen $\left(\mathrm{O}_{2} 95 \%, \mathrm{CO}_{2} 5 \%\right)$ was maintained at a constant temperature $\left(32^{\circ} \mathrm{C}\right)$. The force in grams was measured with an isometric transducer linked to a power lab data acquisition system.

Electrically stimulated muscle contractions: The intramural nerves within the ileal strips were excited by rectangular pulses of $2 \mathrm{~ms}, 25$ $\mathrm{mA}$ and a frequency of $0.2 \mathrm{~Hz}$. Transmural stimulation was applied using two platinum electrodes, one placed in the lumen of the ileum and the other outside the tissue.

CCK-5, penta-gastrin and cholecystokinin CCK-8 preparations: CCK-8S was dissolved in distilled water to prepare a stock solution of $500 \mu \mathrm{M}$ solution, from which cumulative additions of increasing concentrations $(0.1 \mathrm{nM}, 1 \mathrm{nM}, 5 \mathrm{nM}, 10 \mathrm{nM}, 20 \mathrm{nM}, 30 \mathrm{nM}$, and 40 $\mathrm{nM}$ ) were tested to plot a dose response curve. Test molecules and lorglumide were added to the organ bath 10 minutes before exposure to the next CCK-8S serial concentrations. The same protocol was used for pentagastrin, CCK-5.

\section{Molecular modeling}

For target preparation the protein structures, pdb identifier 1HZN for the $\mathrm{CCK}_{1}$ and $1 \mathrm{~L} 4 \mathrm{~T}$ for the $\mathrm{CCK}_{2}$-gastrin receptor were downloaded from the protein data bank (www.rcs.org) and docking was performed using Autodock Vina and Hex. After several docking trials for the $\mathrm{CCK}_{1} / \mathrm{CCK}_{2}$ receptor the results were analysed and visualized using
Chimera and Designer studio 4.5. After visual inspection the results were presented to rationalize drug ligand interactions with the each CCK receptor subtype.

\section{Allograft study}

\section{In vivo experiments in mice - assessment of anti-tumour inhibition}

Pure strain NMRI mice aged between 6 and 8 weeks from our inbred colony were used for transplanting MAC (murine colon cancer) tumours. Animals were fed on RM3E diet (Lillco-England) and water ad libitum. Approximately $2 \mathrm{~mm}$ cubes containing $2 \times 10^{5}$ cells of MAC 16 tumour fragments were transplanted subcutaneously in the inguinal region via a trocar in a volume of $0.2 \mathrm{ml}$. Tumour bearing mice were randomised in groups of 7 animals per group and the treatment was started 10 days after transplantation. The test compounds were administered in propylene glycol. The effect of chemotherapy was assessed 20 days after transplantation. Mice were killed after 10 days of drug treatment and the effects were measured by the differences in tumour weight as expressed: \%.inhibition $=$ Treated weight control weight $\mathrm{x} 100$.

The body weight changes were recorded additionally. The procedure was approved by the home office and the bioethics committee of Aston University.

\section{Xenograft study in NSG mice}

1 million cells were used per mouse and the test molecule was administered in $20 \%$ DMS0 $+80 \%$ PEG-300. The suspension was vortexed and warmed at $37{ }^{\circ} \mathrm{C}$ for $5 \mathrm{~min}$ to ensure dissolution. MAC 16 mouse chemo resistant colon cancer cells were grown in RPMI medium supplemented with $10 \%$ fetal bovine serum (FBS) in $37^{\circ} \mathrm{C}$ incubator with $5 \% \mathrm{C}_{2}$. Human cancer cells were grown in DMEM supplemented with $10 \%$ FBS in $37^{\circ} \mathrm{C}$ incubator with $5 \%$ $\mathrm{CO}_{2}$. Cells were grown until $70 \%$ confluence before passaging into fresh flasks. For xenograft implantation, above indicated cells were harvested, viable cells determined by trypan blue exclusion, and a cell suspension in growth medium was prepared. The cell suspension in growth medium (100-111/mouse) was implanted subcutaneously in NSG mice. Once tumours reached $100 \mathrm{~mm}^{3}$, the animals were randomized within the respective cell line and treated orally. Body weight and tumour volume were measured thrice weekly (Mon, Wed, and Fri). Animals were sacrificed ( 6 hrs after the last dose) when the tumours reached over $1500 \mathrm{~mm}^{3}$ or when the animals lost over $20 \%$ body weight.

All experiments were performed in compliance with the relevant laws and institutional guidelines and the institutional bioethics committee has approved the experiments.

\section{PK analysis}

6-8 week male rats purchased from Harlan Research Laboratories, North America Registration Number: Syngene-IAEC-412-08-2013 aged 6 to 8 weeks old Identification : They were identified individually with tail marking using permanent marker Acclimatization : At least for one week under laboratory conditions, after veterinary examination. Only animals without any visible signs of illness were used for the study.

Time points for blood sampling (IV dose) were pre-dose, 0.083 , $0.25,0.5,1,2,4,6,8, \& 24 \mathrm{hr}$ post dose (10 time points). Time-points for blood collection (PO dose) was, pre-dose, 0.25, 0.5, 1, 2, 4, 6, 8, $\& 24 \mathrm{hr}$ post dose ( 9 time points). At each time point, approximately $150 \mu \mathrm{L}$ of blood was collected through jugular vein in labeled tubes 
containing K2-EDTA as anticoagulant. The tubes were mixed gently and centrifuged at $2500 \mathrm{~g}$ for 10 minutes at $4^{\circ} \mathrm{C}$. The plasma was separated into labeled polypropylene tubes $(\sim 75 \mu 1$ of plasma) and stored immediately at $-80^{\circ} \mathrm{C}$ until analysis.

Analysis of samples by LC-MS/MS was done using API Sciex 4000 system operated with Nexera ${ }^{\mathrm{TM}}$ UHPLC (Shimadzu) as frontend. Samples were separated on a Phenomenex kinetex C18 (50X2.1 $\mathrm{mm}, 5 \mu$ ) using a gradient mode at a flow rate of $1 \mathrm{ml} / \mathrm{min}$. The mobile phase consisted of $0.1 \%$ formic acid in MilliQ water (A) and $0.1 \%$ formic acid in acetonitrile (B). MS instrument was operated in positive mode. The multiple reactions monitoring transition of test molecule was 247.9/192.0 (Q1/Q3) with a declustering potential of $70 \mathrm{~V}$, entrance potential $10 \mathrm{~V}$, and collision energy of $25 \mathrm{~V}$. The curtain gas $(5 \mathrm{~V})$, ion-spray voltage $(5500 \mathrm{~V})$, temperature $\left(500^{\circ} \mathrm{C}\right)$, nebulizer gas (GS1), and auxiliary gas (GS2) were set at 45 psi \& 55 psi respectively, and the interface heater was on.

\section{Statistical methods}

The data were expressed as mean $\pm \mathrm{SD}$ and one-way analysis of variance (ANOVA) and supplementary Tukey test for pairwise comparison were tested to determine for any significant difference at $\mathrm{p}<0.05$.

\section{Results and discussions}

\section{SAR optimisation}

The first step was to screen for potent binding affinity and to identify a $\mathrm{CCK}_{1}$ or $\mathrm{CCK}_{2}$-selective ligand for subsequent in vitro and in vivo evaluation. Using radiolabelled iodinated cholecystokinin, inhibition of binding was determined for all test molecules and the $\mathrm{IC}_{50}$ are outlined in Table 1. Lorglumide served as $\mathrm{CCK}_{1}$ standard and L-365,260 was used as $\mathrm{CCK}_{2}$ standard. The ring enlargement from a 3- membered to a 5- membered ring system (entry 11-12) resulted in no significant increase of binding affinity.

Table I CCK binding affinity expressed in $\mathrm{IC}_{50}$ in micromolar using iodinated hot $\mathrm{CCK}_{8}$ as radioligands with cortex and pancreatic membranes; $\mathrm{N}=3$

\begin{tabular}{|c|c|c|c|c|}
\hline Lactam & $\mathbf{X}=$ & $\mathbf{R}=$ & CCKI $[\mathrm{mM}]$ & $\mathrm{CCK} 2[\mathrm{mM}]$ \\
\hline 7 & $\mathrm{H}$ & Isobutyl- & $0.020 \pm 0.01$ & $1.2 \pm 0.3$ \\
\hline 8 & $\mathrm{Cl}$ & Isobutyl- & $0.008 \pm 0.01$ & $0.4 \pm 0.2$ \\
\hline 9 & $\mathrm{~F}$ & Isobutyl- & $0.012 \pm 0.01$ & $0.75 \pm 0.2$ \\
\hline 10 & $\mathrm{H}$ & t-butyl- & $0.12 \pm 0.22$ & $0.9 \pm 0.03$ \\
\hline II & $\mathrm{H}$ & Cyclopentyl- & $0.36 \pm 0.03$ & $0.84 \pm 0.2$ \\
\hline 12 & $\mathrm{Cl}$ & Cyclopentyl- & $2.5 \pm 0.03$ & $>10$ \\
\hline 13 & $\mathrm{H}$ & Hexyl- & $4.5 \pm 0.3$ & $>10$ \\
\hline 14 & $\mathrm{Cl}$ & Hexyl- & $3.6 \pm 0.3$ & $>10$ \\
\hline 15 & $\mathrm{H}$ & Cyclohexyl- & $2.5 \pm 0.3$ & $>10$ \\
\hline 16 & $\mathrm{H}$ & $\mathrm{Ph}-$ & $>10$ & $>10$ \\
\hline 17 & $\mathrm{H}$ & $\mathrm{Bz}-$ & $0.85 \pm 0.03$ & $0.020 \pm 0.005$ \\
\hline 18 & $\mathrm{Cl}$ & $\mathrm{Bz}-$ & $0.5 I \pm 0.004$ & $0.022 \pm 0.004$ \\
\hline 19 & $\mathrm{~F}$ & $\mathrm{Bz}-$ & $0.1 I \pm 0.004$ & $0.012 \pm 0.004$ \\
\hline 20 & $\mathrm{~F}$ & P-F-Bz- & $0.080 \pm 0.004$ & $0.018 \pm 0.004$ \\
\hline 21 & $\mathrm{H}$ & Methylbenzyl- & $0.6 \pm 0.04$ & $0.021 \pm 0.01$ \\
\hline 22 & $\mathrm{H}$ & Methylbenzyl- & $0.42 \pm 0.03$ & $0.21 \pm 0.05$ \\
\hline 23 & $\mathrm{H}$ & Phenylethyl- & $>10$ & $0.022 \pm 0.002$ \\
\hline 24 & $\mathrm{Cl}$ & Phenylethyl & $>10$ & $0.030 \pm 0.001$ \\
\hline Lorglumide & & & $0.17 \pm 0.01$ & $>10$ \\
\hline L-356,260 & & & $0.25 \pm 0.01$ & $0.003 \pm 0.001$ \\
\hline
\end{tabular}

The change from N-propyl into the N-butyl group resulted in a manifold increase of activity and the best substituent on the central nitrogen atom was found iso-butyl, as seen for derivative 7. The introduction of a halogen atom into the para- position of the phenyl group resulted in an increase of binding affinity as observed in lactame 8 and lactame 9. Lactame 9 of equipotent binding affinity was obtained as crystalline material in better yields than the chlorinated analogue.
The iso-butyl group on the $\mathrm{N}$-atom produced the best overall ligand, with $\mathrm{CCK}_{1}$ selectivity and the $\mathrm{IC}_{50}$ was reduced significantly for t-butyl derivative 10 . The $n$-pentyl analogue was formed in very low yields and the n-hexyl lactames 13,14 clearly lost binding affinity and the same was observed for the cyclohexyl derivative 15 .

Lactames, such as pyrrolone 16, containing an aromatic ring, directly connected to the N-position, showed a micromolar activity $>$ 
$10 \mathrm{mM}$. Most interestingly, the introduction of an N-benzyl substituent to the pyrrolone template, instead of an alkyl group, resulted in nonselective CCK-ligand, pyrrolone 17. Again, halogen atoms, such as chlorine, only marginally changed the binding affinity for the chlorinated N-benzyl lactame 18 . The introduction of fluorine resulted in a significantly improved binding affinity, thus providing us with a mixed CCK antagonist.

A second para fluorine in the benzyl position did not enhance binding affinity any further, but due to inhibition of para hydroxylation, resulted in a molecule with manifold oral bioavailability, lactame 20. The introduction of a chiral amine, such as methyl benzyl amine provided diastereoisomers (Entry 21, 22), which were separated by column chromatography, and both stereoisomers occurred a lower affinity than the parent benzyl derivative 17 .

The introduction of a spacer, a single $\mathrm{CH}_{2}$ group, resulted in a phenyl-ethyl derivative 23 , which represented a highly $\mathrm{CCK}_{2}$ selective ligand. Lactame 23 is 450 times selective for the $\mathrm{CCK}_{2}$ / gastrin receptor. Halogenation, the introduction of a para- chlorine atom on the phenyl-position, lactame 24, did not enhance binding affinity any further; possibly due to drug receptor interaction of the phenyl group with a lipophilic cavity within the CCK receptor.

Overall, the introduction of alkyl groups, most preferred an isobutyl- group, provided a $\mathrm{CCK}_{1}$ selective antagonist a hydroxylpyrrolone 9 , which was the selected development candidate PNB-028 for colon and pancreatic cancer associated with the $\mathrm{CCK}_{\mathrm{C}}$ receptor. ${ }^{29}$

The N-benzylated pyrrolone 17 displayed a non-selective receptor binding profile and served as lead structure for optimisation. The benzylated fluoro-analogue 19 served as optimised molecule for preclinical pharmacological evaluation as PNB-091 until bioavailability was taken into consideration at a later development stage (Figure 2)
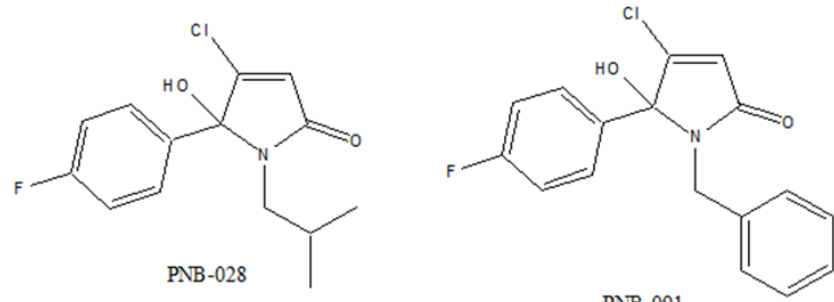

PNB-091

Figure 2 Overview of selected molecules.

\section{Molecular modelling}

Molecular modelling studies were performed for isobutyl derivative with the $\mathrm{CCK}_{1}$ receptor (Figure 3a).

The isobutyl group of the ligand interacted with a hydrophobic cave of the receptor, centred at Ala-14. The carbonyl group in the 2-position bond via hydrogen binding towards the CCK receptor with Arg-9 and the $\mathrm{N}$ - atom of the lactam interacted with Glu-17. The 5-hydroxygroup of the ligand displayed interactions with of Asn-6, while the phenyl group has no interaction with tryptophan or phenylalanine. Pi - alkyl interactions only may explain the small increase in binding affinity of the chlorinated analogue of PNB-081, based on interaction with Leu-29 and Ile-28. If the para phenyl position is not blocked by the chorine atom, most interestingly, the proposed metabolite can interact with the $\mathrm{CCK}_{2}$ receptor. It is supposed that lactam 7, is hydroxylated in the para phenyl position by P450 and this metabolite may interact with the $\mathrm{CCK}_{2}$ receptor via His 122 interaction. Most interestingly hydroxylation may also enhance $\mathrm{CCK}_{1}$ affinity due to interactions with Arg 9.

The docking of lactame 23 into the $\mathrm{CCK}_{2}$ receptor is outlined in Figure $3 \mathrm{~b}$ and some key interactions are highlighted for one final pose of minimal energy (Figure 3b).

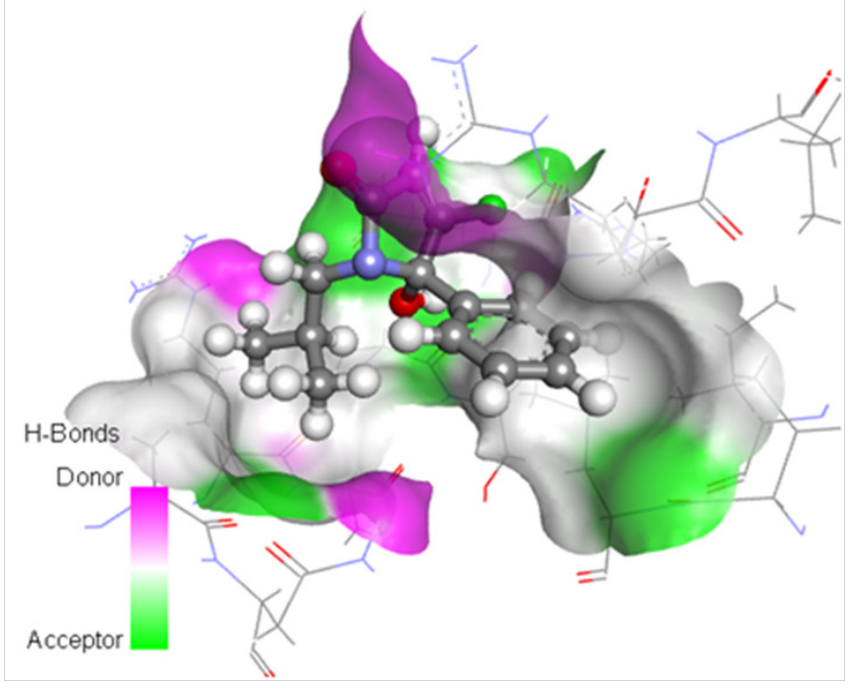

Figure 3a Drug receptor interactions of isobutyl lactam and the CCK, receptor.

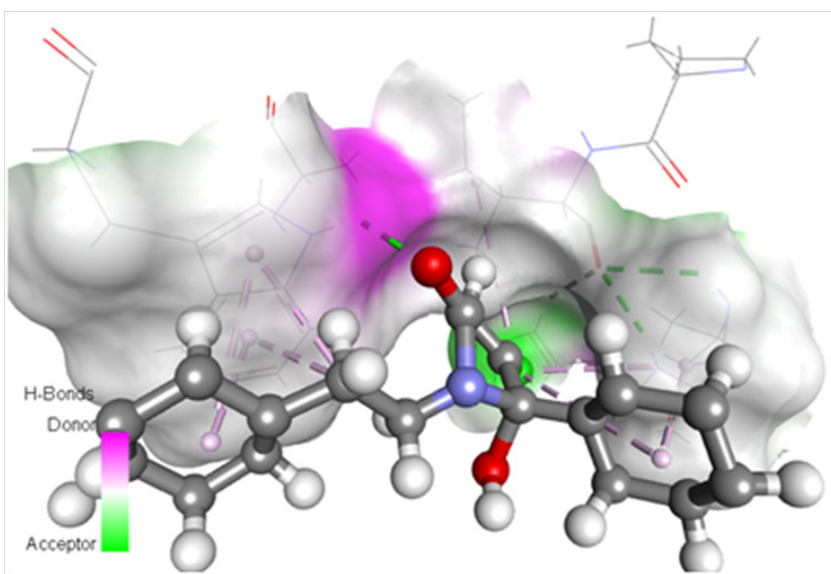

Figure 3b Docking of CCK antagonist lactame 23 into the $\mathrm{CCK}_{2}$ receptor.

The 5-hydroxy group of the central pyrrolone template interacted via hydrogen binding with the $\mathrm{N}$ group of Trp114. The phenyl group of the N-phenylethyl- side chain bound to the aromatic indole system of Trp114 and electron withdrawing groups may enhance these aromatic interactions. The lipophilic pocket allowed principally a wide range of substituents, but only phenyl and not cyclo-hexyl could be realised synthetically. The 5- phenyl group of the pyrrolone template bound via Ile 184 and Leu 133, based on van der Waals interactions and not aromatic interactions. The introduction of electron withdrawing groups, such as halogen atoms, is therefore not enhancing affinity and optimisation on this side is with limited effect. Overall, the observed binding affinity and the predicted interaction based on molecular modelling interaction correlated well for the cholecystokinin and the gastrin receptor. 


\section{Pharmacology}

\section{Isolated tissue preparations: from ligands to antagonists}

Opiate agonists, such as morphine and CCK antagonists, such as lorglumide and devazepide reduced electrically induced contractions on the GPI. From the radioligand binding assay the pyrrolones were identified as potent ligands, and the classical isolated tissue preparation served as initial functional assay, confirming the antagonistic properties of these ligands.

Using the isolated rat duodenum preparation, stable amplitude was generated and a reduction of this amplitude was observed dose dependently for lactame 19, which is outlined in Figure 4. This assay represents a fast and efficient way to screen for CCK antagonists using classical isolated tissue preparations. PNB-091 acted as much lower concentrations than lorglumide, the CCK standard.

Cholecystokinin, $\mathrm{CCK}_{8 \mathrm{~s}}$, induced contractions of the guinea pig gall bladder and this second tissue based assay was applied to reconfirm with this standard preparation the antagonistic properties of the potent CCK ligands (Figure 5).

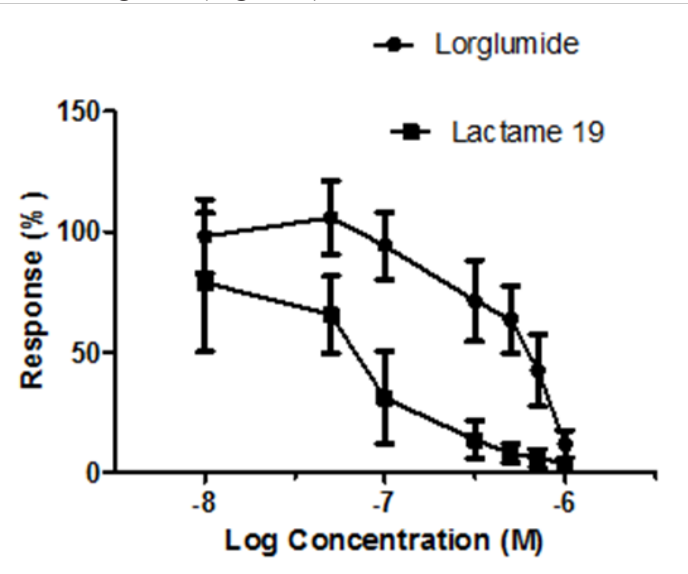

Figure 4 Concentration - response curves of lactame 19, PNB-09I and lorglumide on electrically induced contractions of the rat intestine.Values are mean \pm standard error of mean, $n=3$. Vertical lines represent error bars.

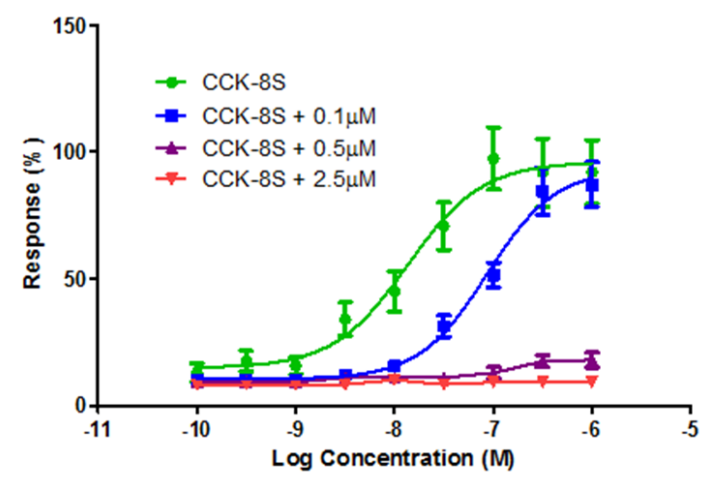

Figure 5 Log concentration-response curves obtained in the presence of CCK-8S alone and CCK-8S in the presence of lactame 19.

CCK-8s induced contractions of the gall bladder and rat duodenum these contractions were reduced dose dependently, which is outlined for the mixed CCK pyrrolone 19 in Figure 5. It appeared that the effect of the antagonist in the rat duodenum assay is insurmountable and an irreversible inhibitor is ideal for the development of antineoplastic agents.
The function of the fluorine atom in PNB-091 was found dual to firstly enhance binding affinity and secondly to block metabolism of the molecules in the para - phenyl position, thus enhancing oral bioavailability.

From 24 molecules in Table 1 the isobutyl substituent and the benzyl group on the $\mathrm{N}$ were recognized essential and 2 series of close analogues were screened in vitro using cell based assays.

\section{Cell based in Vitro Assay}

CCK antagonists are associated with an array of therapeutic applications, but the focus of our research programme was to provide a non-toxic orally available CCK antagonist for the treatment of cancers. The antineoplastic properties of selected NCE and standard CCK antagonists, such as L-365,260 ( $\left(\mathrm{CCK}_{2}\right)$, devazepide and lorglumide $\left(\mathrm{CCK}_{1}\right)$ were subsequently investigated; using a range of CCK associated cancer cell lines.

In vitro tests were originally performed using a cell count assay, as the aim was to inhibit proliferation and not to optimise cytotoxicity, but the results were identical in the methylthiazolyltetrazolium (MTT) assay, possible due to induced apoptosis. It was screened for an inhibitor of viability in certain CCK related cancers cell lines using the MTT assay.

Miapaca is a human pancreatic carcinoma cell line and selected data are outlined in Table 2. Pyrrolone 9 was found 20 times better in terms of $\mathrm{IC}_{50}$ concentrations than lorglumide. Devazepide, which gave an $\mathrm{IC}_{50}$ about $1 \mu \mathrm{M}$ showed agonistic activity (unpublished results). Lorglumide, a $\mathrm{CCK}_{1}$ antagonist, was acting on the gallbladder $\mathrm{CCK}_{1}$ receptor and not the pancreatic CCK receptor. None of the known CCK antagonists, devazepide or lorglumide proved to be clinical useful, which is in line with our results.

The PANC cell line is a human pancreatic cell line. Pyrrolone 9 is many times better than devazepide / lorglumide on this selected pancreatic cell line. Cancer treatment is combination therapy, even for hormone dependent cancers. For this pancreatic cell line the synergistic effects of MK-329 = devazepide in conjunction with cisplatin were reported. ${ }^{24}$ and studies to investigate pyrrolone 9 , which is now PNB-028 with cis - platin and 5-FU are ongoing.

Overall, pyrrolone 7-9 were not significantly different from each other and the parent pyrrol 7 and the fluorinated pyrrolone 9 were tested subsequently in vivo in xenograft models under consideration of their bioavailability. In vitro in cell based assays they were found of equal selective toxicity towards 2 human pancreatic and 2 colon cancer cell lines. The cytotoxicity results for CCK related cell lines are outlined in Table 2 with lorglumide and devazepide as $\mathrm{CCK}_{1}$ standard and L-365,260 as $\mathrm{CCK}_{2}$ standard.

The antineoplastic effect, mediated by blocking CCK receptors, which are expressed in parts of the GI system, correlated well in vitro cell culture and isolated tissue preparations. MAC 13 and MAC 16 cancers are derived from the colon of the mouse and MAC 16 is of particular interest, as it is resistant to alkylating agents.

For pyrrolone 7 , an $\mathrm{IC}_{50}$ about $100 \mathrm{nM}$ was determined for the $\mathrm{MAC}$ 16 cell line and the fluorinated analogue 9 was slightly more potent. Most interestingly, no other CCK antagonist, such as L-365,260, devazepide or lorglumide was found active for this cell line, which is, when transplanted into mice lethal within weeks. Therefore, it may be concluded, that the unsurmountable irreversible properties of the antagonists are key to colon cancer. 
Table 2 Cytotoxicity assay, IC $\mathrm{C}_{50}$ of selected examples against a variety of $\mathrm{Gl}$ and brain cell lines. IC50 values are based on inhibition of viability in the MTT assay in various cell lines

\begin{tabular}{|c|c|c|c|c|c|c|c|}
\hline IC50 [nM] & MIA PACA & PANC & MACI 3 & MACI 6 & U373MG & SHSY5Y & U-87 \\
\hline L-365,260 & $>5000$ & $>1000$ & $>5000$ & $>5000$ & $54 I \pm 87$ & $44 I \pm 54$ & $841 \pm 88$ \\
\hline Devazepide & 1200 & $480 \pm 32$ & 1100 & 1000 & $>5000$ & $987 \pm 87$ & $562 \pm 87$ \\
\hline Lorglumide & $425 \pm 23$ & $3|6 \pm 2|$ & $421 \pm 11$ & $861 \pm 22$ & $>5000$ & $>5000$ & $>5000$ \\
\hline Pyrrolone 7 & $15 \pm 4$ & $27 \pm 9$ & $536 \pm 32$ & $96 \pm 25$ & $765 \pm 29$ & $>5000$ & $>5000$ \\
\hline Pyrrolone 8 & $13 \pm 4$ & $22 \pm 9$ & $526 \pm 34$ & $86 \pm 23$ & $475 \pm 25$ & $>5000$ & $>5000$ \\
\hline Pyrrolone 9 & $I I \pm 4$ & $18 \pm 6$ & $508 \pm 35$ & $76 \pm 20$ & $665 \pm 28$ & $23 I \pm 2 I$ & $|4| \pm||$ \\
\hline Pyrrolone 17 & $230 \pm 11$ & $674 \pm 33$ & $>1000$ & $>1000$ & $23 \pm 3$ & $18 \pm 7$ & $14 \pm 8$ \\
\hline Pyrrolone 19 & $230 \pm 11$ & $674 \pm 33$ & $>1000$ & $>1000$ & $8 \pm 4$ & $\mid I \pm 2$ & $18 \pm 6$ \\
\hline Pyrrolone 20 & $230 \pm 11$ & $674 \pm 33$ & $>1000$ & $>1000$ & $20 \pm 4$ & $13 \pm 4$ & $15 \pm 4$ \\
\hline
\end{tabular}

The anticancer activity of the agents is not limited to GI cancers. The cytotoxicity of the glioblastoma cell line U373MG, a brain cancer cell line, was determined for a small series of test compounds including for Merck's CCK, antagonist L-365,260. The CCK antagonist, pyrrolone 7 and L-365,260 were found of high nanomolar activity. The mixed CCK antagonist, benzylated pyrrolone 17 showed low nanomolar activity and key was to improve the oral bioavailability. The fluorinated pyrrolone 19 with enhanced receptor binding affinity provided a molecule with best in vitro activity on this humane brain cancer cell line. The introduction of a second fluorine atom for pyrrolone 20 furnished a molecule with similar binding affinity and cell based activity, but due to inhibition of the hydroxylation site, a 3 fold oral bioavailability was obtained.

A mixed antagonist may work best for treating brain cancers, as mengionomas express $\mathrm{CCK}_{1}$ receptors and astrocytomas $\mathrm{CCK}_{2}$ receptors. ${ }^{25} \mathrm{~A}$ human glioma cell line, U-87 responded to $\mathrm{CCK}_{2}$ antagonists, ${ }^{26}$ occurred higher IC value in contrast to SHSY5Y is a further neuroblastoma human cell line reduced level of CCK expression. Most remarkable for this cell line the best inhibition of growths was obtained cell based, indicating possibly the blockage of other non-CCK pathways.

Subsequently, this tumour was studied initially in mice to analyse, if the in vitro results could be translated into relevant anti-tumour activity.

\section{Animal studies in mice}

\section{Colon cancer in vivo study}

MAC 16 tumours developed quickly within 6 days after implantation and grew robustly. Once the tumours reached $100 \mathrm{~mm},{ }^{3}$ the animals were divided into the various treatment groups and treated with vehicle or the fluorinated pyrrolone 9. Iso-butylated pyrrolones inhibited the tumour growth significantly from the day treatment was initiated and maintained tumour inhibitory activity until sacrifice At sacrifice, interestingly in some animals growths were not only inhibited, but tumours shrinked after reaching a maximum volume. Most interestingly, while MAC 16 tumours in the vehicle-treated group metastasized to lungs, tumours in drug-treated groups did not metastasize to lungs (Figure $6 a \mathrm{a} 6 \mathrm{~b}$ ).

The control showed nearly exponential growths for this aggressive tumour. The treatment group by oral administration at optimum level $(100 \mathrm{mg} / \mathrm{kg})$ showed strong inhibition of tumour growths and the regiment study with bi-daily instead of daily dosing intervals (24h-48h) showed enhanced activity and no signs of toxicity. The analysis of body weight showed an expected loss of $20 \%$, which lead to termination at day 7 and for the $48 \mathrm{~h}$ regimen an increase of body weight was found.

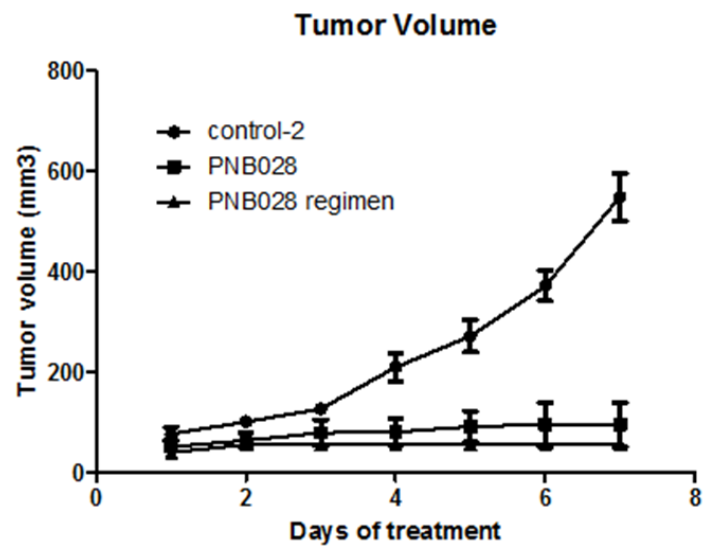

Figure 6a Tumour volume in mice for the treatment with PNB-028 over the period of 7 days.

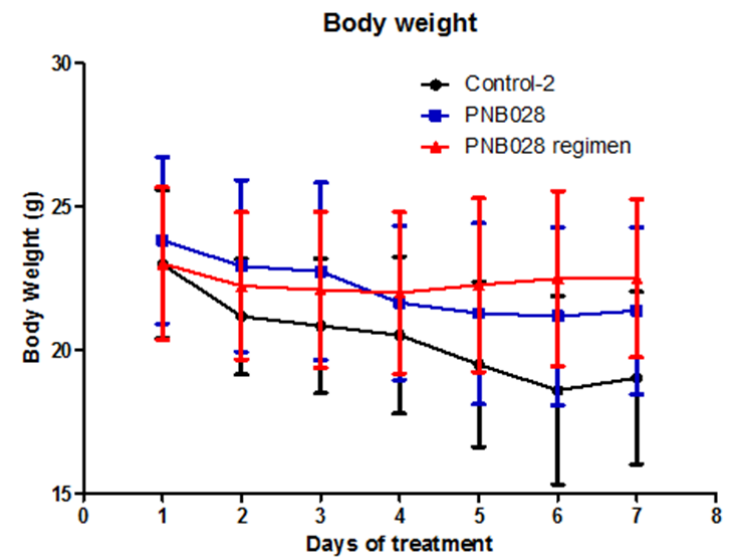

Figure 6b Body weight loss during PNB-028 treatment in mice over the period of 7 days.

Cholecystokinin is known to mediate cancer progression and metastasis, which were antagonised by sufficient concentrations of devazepide..$^{27}$ Colon cancer is generally linked with the $\mathrm{CCK}_{1}$ receptor and only under certain conditions it is associated with the 
$\mathrm{CCK}_{2}$ receptor. ${ }^{28}$ Gastric cancer is correlated with the $\mathrm{CCK}_{2}$ receptor / gastrin receptor and in the human gastric cancer cell line HT-29, gastrin-17 stimulated growths and theses effects were abolished by $\mathrm{CCK}_{2}$ antagonists such as L-365,260. In detail Colucci tested only one $1 \mathrm{nM}$ concentration of devazepide, which stimulated growths in the study and by our own observations. Low nanomolar devazepide concentrations occur in vitro a CCK agonistic effect and this may explain why devazepide showed no significant effect in cancer previously. $^{12}$

Overall for the MAC 16 cell line proliferation was blocked in vitro and in vivo by our pyrrolone based CCK antagonist PNB028. Here, the link $\mathrm{CCK}_{1}$ receptor and colon cancer was confirmed experimentally.

Efforts to elucidate the underlying anticancer action were made and no significant apoptosis and no influence on angiogenesis by angiogenesis marker CD34, was observed. Proliferation, analysed by proliferation marker KI67, was performed and the results were outlined in Figure 7.

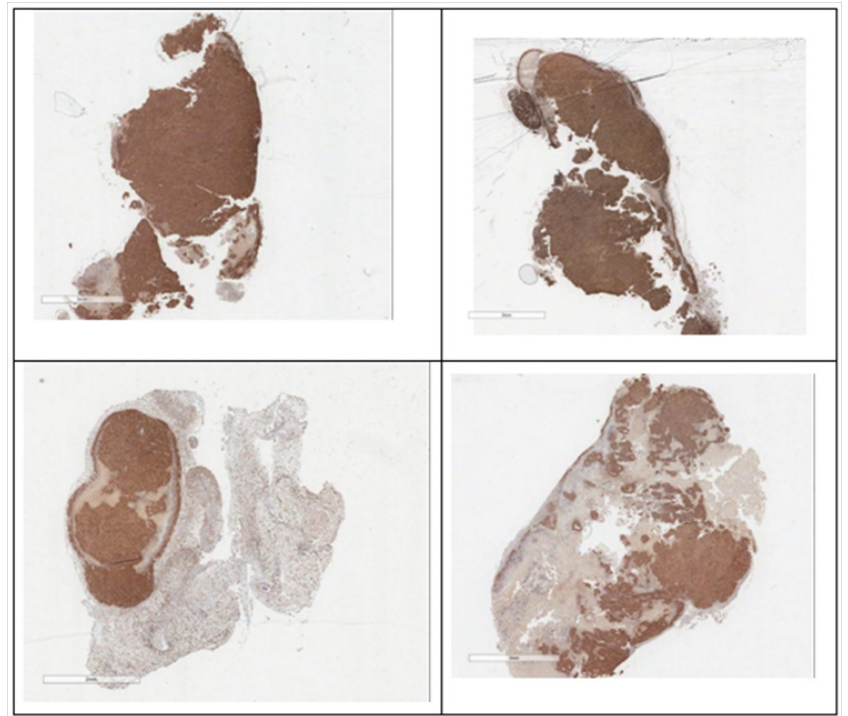

Figure 7 Histology. Ki67 staining: top control, bottom PNB-028 treated 50 $\mathrm{mg} / \mathrm{kg}$ by $\mathrm{PO}$ administration.

For the minimal dose of $50 \mathrm{mg} / \mathrm{kg}$ in mice, the tissue was stained (TOP) and in the treatment group large white areas of proliferation free tissue was seen.

These findings are particularly important for the understanding of the standard colon cancer biomarker CEA. Dell death, as a result of apoptosis caused by Pt agents and antimetabolite 5-FU resulted in an increase of biomarker CEA, followed by a decline from week 4 onwards in man.

In the previous communication initial data on pancreatic cancer was shown, and here, under the consideration of oral bioavailability a study was performed in immunosuppressed mice under consideration of oral bioavailability.

For lactam 7 the parent hydroxyl-pyrrolone 7 an oral bioavailability was determined as $24 \%$ in rats for the $10 \mathrm{mg} / \mathrm{kg}$ dose. Pyrrolone 9 , assigned as PNB-028 had $98 \%$ oral bioavailability and represents the $\mathrm{CCK}_{1}$ antagonist with the highest known bio-availability of all published molecules. The analysis of the plasma concentration in rats was analysed for lactam 7 (24\%) and is outlined in Figure 8a.
The selected benzylated pyrrolone 19 (Figure 8b) showed $15 \%$ oral bioavailability for the $10 \mathrm{mg} / \mathrm{kg}$ dose in rats and further SAR optimisation was achieved by inhibiting metabolism in the para hydroxyl position. The introduction of a second fluorine atom had little influence on binding affinity, but enhanced bioavailability to $34 \%$.

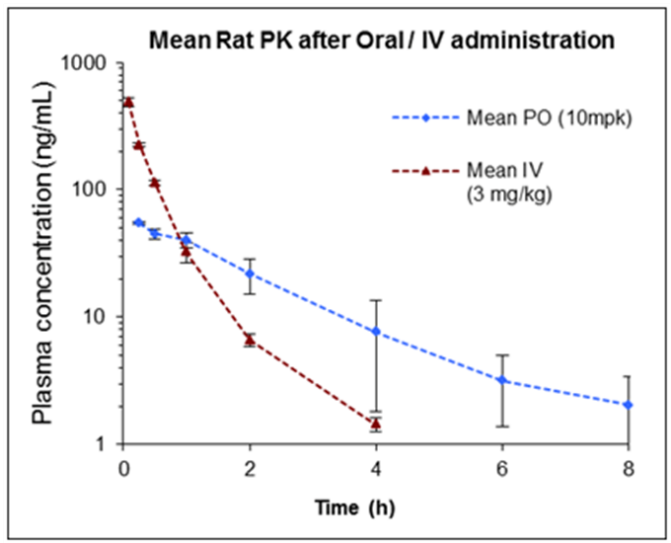

Figure 8a Kinetics of isobutyl lactam 7.

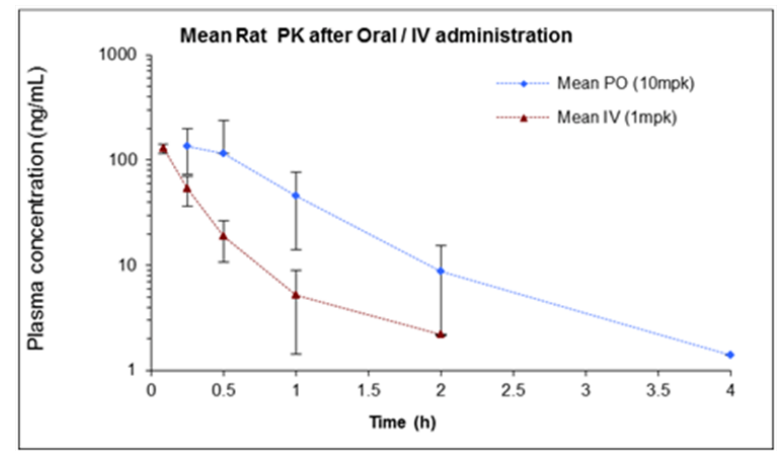

Figure 8b Kinetics of Benzyl lactame 19, PNB-091.

All relevant molecules are outlined in Figure 9 and a SAR optimisation with respect to metabolism was elucidated. The isobutyl group, as aliphatic side chain, is inert towards metabolism and the initial bioavailability for the pyrrolone 7 is medium. After the introduction of a fluorine atom a nearly full oral bioavailability was achieved for this molecule PNB-028. This CCK antagonist occurred the best bioavalability compared to present competitors and will enable us the achieve plasma concentrations to shut down CCK mediated cancer growths pathways.

The benzylated pyrrolone 17 had initially a poor bioavailability of $1.7 \%$ and first fluorination nearly enhanced bioavailability nearly 10 fold for 19 , PNB-091 to $15 \%$. A second halogenation inhibiting the hydroxylation of the N-benzyl substituent on the para position resulted in a further 2 fold increase (lactam 20), giving a 34\% oral bioavailability. Fortunately, the fine chemical 4-fluoro-benzylamine is slightly more costly than the industrial benzyl-amine, thus overall reducing the costs of production of the fully optimised molecule 20 , which entered preclinical development as PNB-291 for the treatment of brain cancers.

\section{Pancreatic cancer xenograft study, MIAPACA tumour}

MIAPACA tumours developed quickly after implantation and grew modestly, though not as robustly as MAC16 tumours. Once 
the tumours reached $100 \mathrm{~mm},{ }^{3}$ the animals were divided into various treatment groups and were treated with vehicle or respective drugs. Though vehicle-treated MIAPACA tumours grew from $100 \mathrm{~mm}^{3}$ to over $750 \mathrm{~mm}^{3}$ within 3 weeks, pyrrolone treated tumours grew slower. Based on bioavailability, the fluorinated isobutylpyrrolone 9 was administered at $20 \mathrm{mg} / \mathrm{kg}$ and the parent isobuyl prrrolone 7 at $60 \mathrm{mg} / \mathrm{kg}$ and after initial faster action the fluorinated pyrrolone 9 at the equivalent dose reduced total inhibition of tumour growths above $90 \%$.

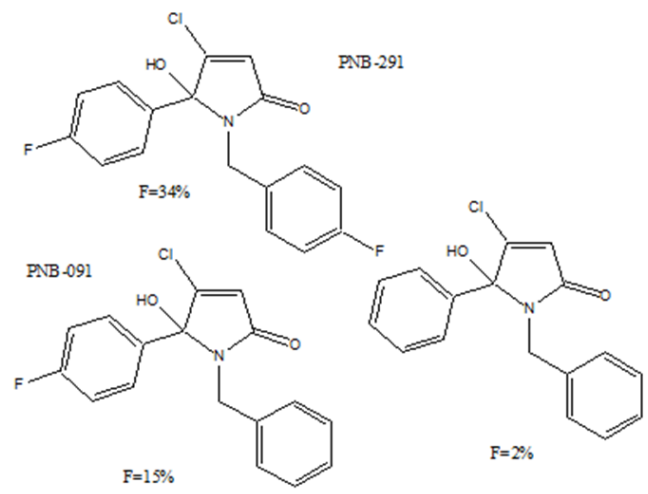<smiles>CC(C)CN1C(=O)C=C(Cl)C1(O)c1ccccc1</smiles>

$\mathrm{F}=24 \%$

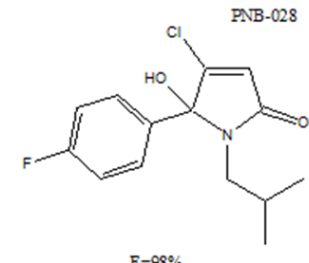

Figure 9 SAR of bioavailability. Sites of metabolism.

Both agents inhibited tumour growth significantly from the day treatment was initiated and maintained the growth inhibitory properties until sacrifice (Figure 10).

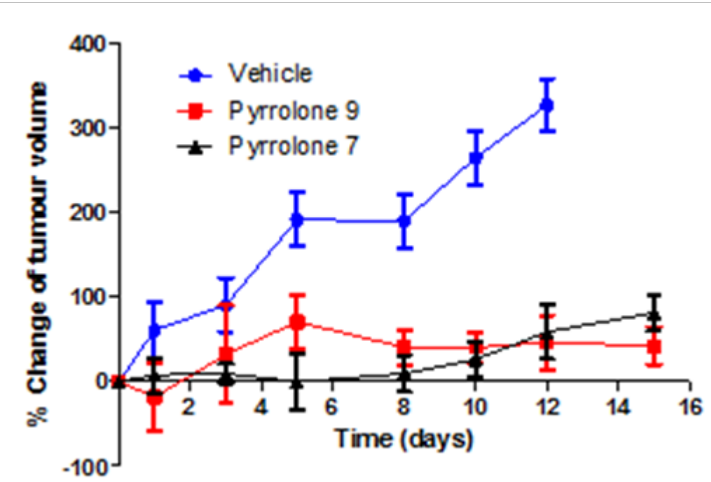

Figure 10 Effect of pyrrolone 7 and 9 on MIAPACA pancreatic cancer tumour growth.

Overall, it was clearly shown, that colon and pancreatic cancers response to $\mathrm{CCK}_{1}$ antagonists and not $\mathrm{CCK}_{2}$ antagonists. ${ }^{29}$ We agree, it is unlikely that, gastrin is more important in pancreatic cancer than cholecystokinin. It may be wise to say, that it is pancreozymin, via the pancreatic cholecystokinin receptor, that promotes cancer $\left(\mathrm{CCK}_{1 \mathrm{~b}}=\right.$ pancreozymin receptor and not $\mathrm{CCK}_{1 \mathrm{a}}$ cholecystokinin receptor) or possibly the CCK-C receptor. Smith clearly stated the role of the CCK-C receptor in pancreatic cancer. ${ }^{30}$ and reviewed the cholecystokinin receptor as molecular target in treating pancreatic cancer. ${ }^{31}$ It is the CCK-C receptor, then according to recent nomenclature -the $\mathrm{CCK}_{3}$ receptor- would be the cancer target and molecular modelling based on the whole receptor, generated by homology modelling would be the starting point for further optimisation towards the $\mathrm{CCK}_{3}$ receptor. This would be advantageous as the $\mathrm{CCK}_{1}$ receptor is required for the physiological role of cholecystokinin. Blocking of the contractions of the gall bladder leads to gallstones in the long term and reductions of bile flow will result generally in liver toxicity.

The benzylated pyrrolones 17, 19 and 20 are mixed CCK antagonists, based on receptor binding confirmed by isolated tissue preparations. In vitro in cell based assays they inhibit proliferation of selected cancer cell line, such as U373MG, SHSY5Y and U-87.

The cell lines differ in CCK expression and the selected cell line in vivo has some expression of the cholecystokinin receptor. The fluorinated pyrrolone 19 was chosen for in vivo evaluation using a humane cell line transplanted into immunosuppressed mice.

\section{Xenograft in vivo brain cancer study}

The fluorinated isobutyl pyrrol 9 has some interesting in vitro activity on cell lines, but for the fluorinated benzyl pyrrolone 19 the lowest $\mathrm{IC}_{50}$ was determined on all 3 selected humane brain cancer cell lines. As a model substance PNB-091 was selected for further in vivo studies using nude mice and the results are outlined in Figure $11 \mathrm{a} \& 11 \mathrm{~b}$

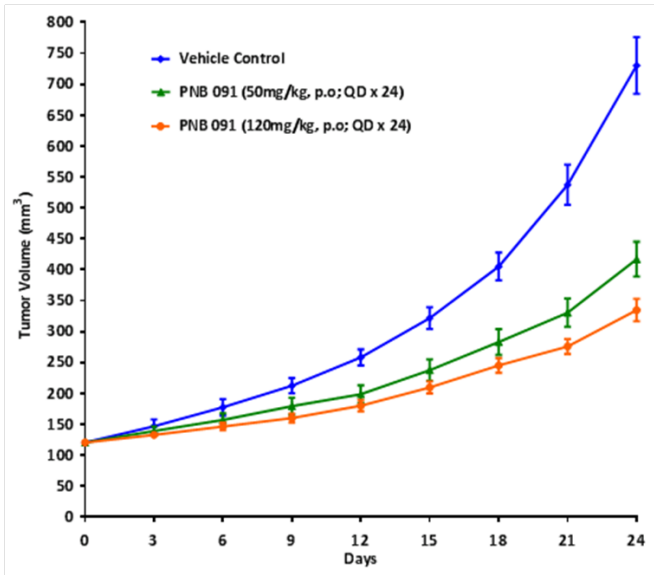

Figure I Ia Change of tumour volume of PNB09I in human U-87 cancer cell lines.

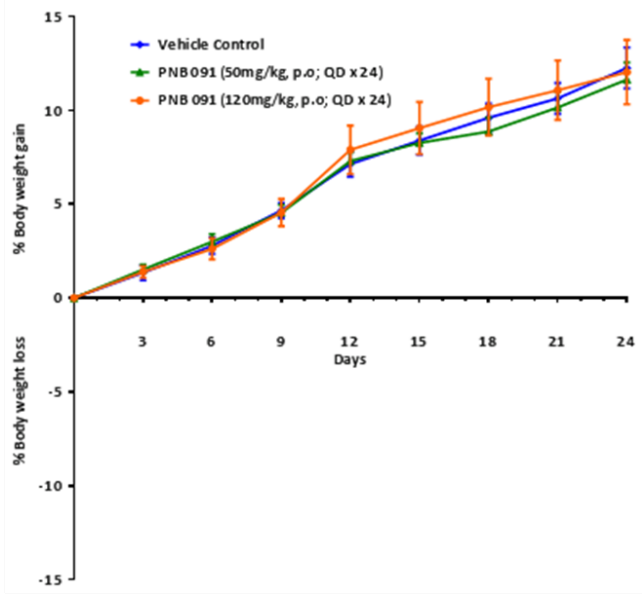

Figure I l b Change of body weight of PNB09I in human U-87 cancer cell lines. 
The transplanted human brain tumour cell line proliferated exponentially and $50 \mathrm{mg} / \mathrm{kg}$ reduced growths significantly and a further reduction was found dose dependently.

No weight loss, an indicator of toxicity was observed, the vehicle was not significantly different even from the highest administered dose and no visual signs of toxicity were found in all mice for the duration of the experiment

According to bioavailability the bis-fluorinated pyrrol on 20 would be efficient at below $30 \mathrm{mg} / \mathrm{kg}$ and this was proofed using MAC16 tumours in mice (not included). 65\% nhibition of brain cancer is significant and $30 \mathrm{mg} / \mathrm{kg}$ in mice would be the equivalent to a $200 \mathrm{mg}$ capsule in man.

\section{Conclusion}

These novel fluorinated pyrrolones PNB-028 and PNB-091/PNB291 were synthesised in only 2 synthetic steps in high overall yields from generally readily available, inexpensive starting material.

Molecules were identified classically in radiolabelled binding assays and SAR was fully optimised for a small series with in vitro cell based assays and tissue based assays. SAR in terms of pharmacokinetics was considered at a very early stage and in vivo evaluation with normal and nude mice resulted in 2 molecules for colon \& pancreatic and a non- selective antagonist for the treatment of brain cancers.

For this novel template, it was found, that irreversible CCK antagonism translated into anti-cancer activity on the gut-brain-axis The known CNS activity of CCK antagonists may be of additional therapeutic benefit in treating cancer -associated diseases, such as pain, anxiety and depression.

\section{Acknowledgements}

The experimental work was partly supported by PNB Vesper Life Sciences.

\section{Conflicts of interest}

No conflict of interest is declared.

\section{Ethical approval}

The animal studies were performed in compliance with relevant laws and institutional guidelines.

\section{References}

1. Maton P, Sutliff V, Jensen R, et al. Carbobenzoxy amino acids: Structural requirements for cholecystokinin receptor antagonist activity. American Journal of Physiology. 1985;248:479-484

2. Herranz R. Cholecystokinin Antagonists: Pharmacological and Therapeutic Potential. Med Res Rev. 2003;23(5):559-605.

3. Mawe $\mathrm{G}$. The role of cholecystokinin in ganglionic transmission in the guinea-pig gall-bladder. J Physiol. 1990;439:89-102.

4. Jorpes E, Mutt V. Cholecystokinin and Pancreozymin, one single Hormone? Acta Physiologica Scandinavica. 1966;66:196-202.

5. Bock MG, DiPardo RM, Mellin EC, et al. Second-generation benzodiazepine CCK-B antagonists. Development of subnanomolar analogues with selectivity and water solubility. $J$ Med Chem. 1994;37(6):722-724.
6. McDonald IM. CCK2 receptor antagonists. Exp Opin Ther Patents. 2001;11:445.

7. Bock MG, DiPardo RM, Mellin EC, et al. Second-generation benzodiazepine CCK-B antagonists. Development of subnanomolar analogues with selectivity and water solubility. $J$ Med Chem. 1994;37(6):722-724.

8. Lattmann E, Arayarat P. From CNS-drugs to anti-neoplastic agents: Cholecystokinin (CCK)-antagonists as modern anti-cancer agents Science (KKU). 2003;31:178-193.

9. Dourish, CT. Cholecystokinin and anxiety. Trends Pharmacol Sci. 1990;11:271.

10. Rasmussen K, Czachura JF, Stockton ME, et al. Electrophysiological effects of diphenylpyrazolidinone cholecystokinin-B and cholecystokinin-A antagonists on midbrain dopamine neurons. $J$ Pharmacol Exp Ther. 1993;264(1):480-488.

11. Dourish CT, Rycroft W, Iversen SD. Postponement of satiety by blockade of brain cholecystokinin-B receptors. Science. 1989;245(4925):15091511 .

12. Chang R, Lotti V, Monaghan R, et al. A potent nonpeptide cholecystokinin antagonist selective for peripheral tissues isolated from Aspergillus alliaceus. Science. 1985;230(4722):177-179.

13. Lattmann E, Billington DC, Poyner DR, et al. Synthesis and evaluation of Asperlicin analogues as non-peptidal Cholecystokinin-antagonists. Drug Design and Discovery. 2001;17:219-230.

14. Evans BE, Rittle KE, Bock MG, et al. Methods for drug discovery: Development of potent, selective, orally effective cholecystokinin-A antagonists. J Med Chem. 1988;31(12):2235-2246.

15. Hahne W, Jensen R, Lemp G, et al. Proglumide and benzotript: Members of a different class of cholecystokinin receptor antagonists. Proceedings of the National Academy of Sciences USA. 1981;8 (10):6304-6308.

16. Makovec F, Chistè R, Bani M, et al. New glutaramic acid derivatives with potent competitive and specific cholecystokinin-antagonistic activity. Arzneimittelforschung. 1985;35(7):1048-1051.

17. Noble F, Wank SA, Crawley JN, et al. International Union of Pharmacology XXI. Structure, Distribution, and Functions of Cholecystokinin Receptors. Pharmacological Reviews. 1999;51(4):745781.

18. Woodruff GN, Hughes J. Cholecystokinin antagonists. Ann Rev Pharmacol Toxicol. 1991;31:469-501.

19. Meyer T, Caplin ME, Palmer DH, et al. A phase $\mathrm{Ib} / \mathrm{II} a$ trial to evaluate the CCK2 receptor antagonist Z-360 in combination with gemcitabine in patients with advanced pancreatic cancer. Eur J Cancer. 2010;46(3):526-533.

20. Offel M, Lattmann P, Singh H, et al. Synthesis of substituted 3anilino-5-phenyl-1,3-dihydro-2H-1,4-benzodiazepinones and their eva-luation as cholecystokinin ligands Archiv der Pharmazie. Chemistry in Life Science. 2006;339:163-173.

21. Lattmann E, Singh H, Boonprakob J, et al. Synthesis and evaluation of N-(3oxo-2,3-dihydro-1Hpyrazol-4-yl)-1H-indole-carboxamide as cholecystokinin antagonists. J Pharm Pharmacol. 2006;58(3):393-401.

22. Lattmann E, Sattayasai J, Boonprakob J, et al. Synthesis and evaluation of N-(5-methyl-3-oxo1,2-diphenyl-2,3-dihydro-1H-pyrazol4yl)-N-phenylureas as Cholecystokinin antagonists. Arzneim Forsch Drug Research. 2005;55:251-258.

23. Lattmann E, Sattayasai J, Boonprakob Y, et al. Chole-cystokinin antagonists (part 1): Antinociceptive, anxiolytic and antidepressant effects of N-(5-methyl-3-oxo-1,2-diphenyl-2,3-dihydro-1Hpyrazol-4-yl)-N'-phenylureas and carboxamides. Drug Discov Ther. 2008;2(3):156-167. 
24. Lattmann E, Billington DC, Poyner DR, et al. Combinatorial solid phase synthesis of multiply-substituted 1,4-benzodiazepines and affinity studies on the CCK2 receptor (Part 1). Drug Design and Discovery. 2002;18:9-21.

25. Lattmann E, Sattayasa J, Billington DC, et al. Synthesis and evaluation of N1-substituted-3-propyl -1,4-benzodiazepine-2ones as Cholecystokinin (CCK2)-receptor ligands. J Pharm Pharm. 2002;54:827-834

26. Lattmann E, Sattayasai J, Schwalbe $\mathrm{CH}$, et al. Analgesic Effects of 5-Alkyloxy-4-amino-2 $(5 \mathrm{H})$-furanones as Cholecystokinin-2 antagonists. Arch Pharm (Weinheim). 2006;349(6):456-465.

27. Lattmann E, Russell ST, Schwalbe $\mathrm{CH}$, et al. Cholecystokinin-1 receptor antagonists: 5-hydroxy-5-aryl-pyrrol-2-ones as anticancer agent. Med Chem Commun. 2006; 7:1138-1145.
28. Lattmann E, Sattayasai ST, Narayanan R, et al. Cholecystokinin-2/ gastrin antagonists: 5-hydroxy-5-aryl-pyrrol-2-ones as antiinflammatory analgesics for the treatment of inflammatory bowel disease. Med Chem Commun. 2016;8:680-685.

29. Ponnusamy S, Lattmann E, Lattmann P, et al. Novel, isoform-selective, cholecystokinin A receptor antagonist inhibits colon and pancreatic cancers in preclinical models through novel mechanism of action Oncology Reports. 2016;35(4):2097-2106.

30. Saita Y, Yazawa H, Honma, Y, et al. Characterization of YM022: its $\mathrm{CCKB} /$ gastrin receptor binding profile and antagonism to $\mathrm{CCK}-8$ induced Ca2+ mobilization. Eur J Pharmacol. 1994;269(2):249-281.

31. Charpentier B, Pelaprat D, Durieux C, et al. Cyclic cholecystokinin analogues with high selectivity for central receptors. Proc Natl Acad Sci U S A. 1988;85(6):1968-1973. 